\title{
A decade of shaping the futures of polar early career researchers: A legacy of the International Polar Year
}

Ruth Hindshaw ${ }^{1}$, Heather Mariash ${ }^{2}$, Trista J. Vick-Majors ${ }^{3}$, Alexander E. Thornton ${ }^{4}$, Allen Pope ${ }^{5,6}$, Yulia Zaika ${ }^{7}$, Josefine Lenz ${ }^{8,9}$, Hanne Nielsen ${ }^{10}$, Gerlis Fugmann ${ }^{11}$

${ }^{1}$ Department of Earth Sciences, University of Cambridge, Downing Street, Cambridge, CB2 3EQ, UK

${ }^{2}$ Wildlife Research Division, Environment and Climate Change Canada, 1125 Colonel By

Dr., Ottawa, Ontario, K1A 0H3, Canada

${ }^{3}$ Flathead Lake Biological Station, University of Montana, 32125 Bio Station Lane, Polson, MT, 59860, USA

${ }^{4}$ Arctic Research Consortium of the United States, 3535 College Road, Suite 101, Fairbanks, AK 99709, USA

${ }^{5}$ International Arctic Science Committee, Borgir við Norðurslóð, 600 Akureyri, Iceland ${ }^{6}$ National Snow and Ice Data Center, CIRES, University of Colorado Boulder, 1540 30th Street, Boulder CO 80303, USA

${ }^{7}$ Faculty of Geography, Lomonosov Moscow State University, Leninskie Gory 1, 119991, Moscow, Russia

${ }^{8}$ Alfred Wegener Institute Helmholtz Centre for Polar and Marine Research, Periglacial Research Section, Telegrafenberg A43, 14473 Potsdam, Germany

${ }^{9}$ University of Alaska Fairbanks, Institute of Northern Engineering, Fairbanks, Alaska, USA

${ }^{10}$ University of Tasmania, Churchill Ave, Hobart TAS 7005, Australia

${ }^{11}$ Association of Polar Early Career Scientists, International Directorate Office, Alfred Wegener Institute, Helmholtz Center for Polar and Marine Research, Telegrafenberg A43, 14473 Potsdam, Germany 


\section{Abstract}

The Association of Polar Early Career Scientists (APECS) is an important legacy of the International Polar Year and continues to foster engagement in education, outreach and communication (EOC) activities relating to the polar regions and provide training for early career researchers (ECRs). Using historical documents, two member surveys and social media statistics we discuss opportunities for training, leadership and skills development related to outreach, such as the annual Polar Weeks and Antarctica Day celebrations. A survey on EOC engagement highlighted the perception that the three main skills gained by participating in an APECS EOC event were networking (75\%), communication (71\%) and interdisciplinary knowledge (65\%). Those who organised events also identified gaining leadership skills such as team management. Thus, participation and engagement in EOC activities actively contributes to career development by enabling ECR to develop valuable soft skills. As a result of the 'bottom-up' organisational structure of APECS there exists a large pool of APECS members who each organise a small number of activities rather than a small core group of very active members who organise the majority of activities, enabling more members to put their soft skills into practice. Additionally, this paper documents the development of APECS over the past decade and highlights the high proportion of female leaders. We demonstrate how the EOC legacy of IPY has continued due to targeted efforts to provide leadership training and to create EOC opportunities for ECRs. 


\section{Introduction}

The 4th International Polar Year (IPY) generated intensive research momentum in both the Arctic and the Antarctic over the two-year period 2007-2009, involving 50,000 participants including researchers, local observers, educators, students and governance personnel from over sixty countries in 228 international research projects (Krupnik et al. 2011). Realising the societal benefit not only of large scientific programs like IPY, but also individual research projects, requires an array of practical soft skills, such as networking, grant writing and communicating with diverse audiences in addition to academic expertise (Schulz, 2008; Harrison, Cohen, Hinchey, Moerke, \& von Dassow, 2009; LeDee et al., 2011). A decade ago the focus on soft skills training in the polar research community was not considered a priority (Provencher et al., 2011). In contrast, today the majority of funding calls require not only research excellence, but also strong collaborations, cross-disciplinary research, skills development and a plan to communicate research outcomes to the general public. For example, since 2009 the Natural Environment Research Council (UK) requires all funding proposals to contain a 'Pathways to Impact' statement (NERC, 2017) and the National Science Foundation (USA) requires a project outcomes report for the general public (since 2010) and a postdoctoral researcher mentoring plan (since 2009) (NSF, 2017). Nevertheless, it can remain challenging for early career researchers (ECRs) to gain experience in soft skills within their traditional graduate programmes or postdoctoral appointments, as they are often absent from academic training (e.g. Kumar \& Hsiao, 2007; Schulz, 2008; LeDee et al., 2011; Gordon 2014; Darlington, Waite, \& Balsdon 2015).

The 4th IPY developed a ground-breaking dedicated campaign to promote education, outreach, and communication (EOC) in the polar sciences by requiring EOC to be an integral part of every IPY endorsed project (Kaiser, Zicus, \& Allen, 2010; Salmon et al., 2011). In this regard, it was successful, with over 550 IPY EOC projects registered in the Polar Outreach Catalogue and an estimated reach of over 14 million people from over 70 countries 
(Provencher et al., 2011). In the subsequent analyses of IPY activities (Provencher et al., 2011), it was highlighted that ECRs were critical to the success the EOC; they understood the importance of EOC activities. The ECR community recognised that there was a need for an organisation to continue the momentum of IPY EOC projects and the training of ECR after IPY.

As a consequence of the increased focus on EOC during the IPY, the Association of Polar Early Career Scientists (APECS) was formed by Jenny Baeseman, Hugues Lantuit, and Rhian Salmon in late 2006 (Baeseman et al., 2011). APECS was initially one among several young researcher initiatives established around the time of the planning of the IPY, including the IPY Youth Steering Committee in 2005, the Permafrost Young Researchers Network (PYRN) in 2005 and the UK Polar Network (UKPN) in 2007. In September 2007, representatives from the various groups met at Sånga-Säby (Sweden) to discuss collaborating and potentially combining efforts to help secure a long term IPY legacy for the training of ECRs (Baeseman et al., 2011). The result of the meeting was the merger of these groups into one large network with the name of APECS. Regional networks like the UKPN, or discipline-specific networks such as PYRN, continued their work and either became National Committees of APECS or retained their own identities while closely cooperating with APECS (Baeseman et al., 2011). APECS was chosen as the name for the merged ECR organisation, as the original APECS had already gained much support from the senior science community. APECS was identified as being the primary organisation responsible for continuing to promote polar EOC activities beyond IPY (Provencher et al., 2011). APECS' goals are to create opportunities for the development of innovative, international, and interdisciplinary collaborations among current ECRs as well as recruiting, retaining, and promoting the next generation of polar enthusiasts by aiming to: (a) maintain a network of polar researchers across disciplines and national boundaries to meet, share ideas and experiences, and develop new research directions and collaborations; (b) offer opportunities for career development towards both traditional and alternative professions related to the polar regions and the cryosphere; (c) promote education 
and outreach as an integral component of polar research (APECS, 2016a, p.2; Baeseman \& Pope, 2011).

Over the years, APECS has grown to be recognised as the voice for ECR within the polar science community and has formal (via Memoranda of Understanding) and informal relationships with most of the international organisations involved in Arctic, Antarctic, alpine, and cryosphere research, as well as education and outreach (APECS, n.d.a). These range from the more education-focused Polar Educators International (PEI) and the University of the Arctic, to the more science-focused Scientific Committee on Antarctic Research (SCAR) and the International Arctic Science Committee (IASC). This expansive network offers APECS members opportunities to engage with multiple actors from primary-school children to international polar policy advisory boards. APECS' network is pivotal to its ability to serve as a hub for international opportunities relevant for early career polar researchers. Building these linkages is of primary importance for building a continuum of leadership if the next generation of researchers and educators are to effectively identify and address $21^{\text {st }}$ century challenges in the polar and alpine regions.

APECS' EOC activities are primarily concentrated in two main events: Polar Weeks and Antarctica Day. International Polar Weeks were initially started during the IPY, first as International Polar Days and in 2009 and 2010 as International Polar Weeks with the theme "What happens at the poles affects us all" (Zicus et al., 2011, p.492; Xavier et al., submitted). In 2012, APECS restarted the International Polar Weeks, organising them twice a year in March and September around the equinoxes when both poles receive 12 hours of daylight. These weeks serve as a concerted focus on polar education and outreach. Each year, APECS and its National Committees lead a programme of EOC events with a strong focus on public engagement. The exact activities vary from year to year but common themes are school visits, online classroom connections to field researchers, public lectures and social media activities. Polar Weeks has been considered an exemplary educational activity for promoting both 
Antarctic science and the Antarctic Treaty System (Portugal, Brazil, Bulgaria, France, \& Kingdom, 2016; Bulgaria \& Turkey, 2017; Xavier, Gray, \& Hughes, in press). Antarctica Day (1 December) was conceived in 2011 by the organisation Our Spaces - The Foundation for the Good Governance of International Spaces in the United Kingdom to celebrate the spirit of international peace and scientific cooperation that signified the signing of the Antarctic Treaty on 1 December 1959. APECS has been a partner to the event from the start and APECS members have worked closely with Our Spaces to translate an educational book on the Antarctic Treaty Celebrating Antarctica: A Treaty Protecting a Continent (Hambrook Berkman \& Pope, 2015) into 22 other languages (Celebrating Antarctica, n.d.).

APECS' EOC activities provide a vehicle with which ECR can learn valuable soft skills such as communication and organisation. In addition, APECS provides in-person training through regular workshops and panel discussions, often connected to large polar conferences such as SCAR Open Science Conference (OSC) and Arctic Science Summit Week (ASSW).

Workshop topics have focussed on a variety of skills including proposal writing, conducting fieldwork, science communication and working with indigenous people (Thomas, Baeseman, Lantuit, Xavier, \& Baker, 2008; Schmale, Lisowska, \& Smieszek, 2013). However, it is not only through the direct work within APECS itself where APECS helps ECRs gain additional skills. Since its inception, APECS has provided leadership opportunities outside of APECS for more than 150 individual ECRs (some of them more than once) to further develop their skills by:

- Nominating them to boards and planning committees of major international polar research-focused organisation such as IASC, SCAR, the European Polar Board (EPB) or the Conservation of Arctic Flora and Fauna (CAFF) working group of the Arctic Council;

- Nominating them to conference committees and as session conveners for major international polar conferences such as the IPY Conferences in 2010 and 2012, the Arctic Science Summit Weeks and the SCAR Open Science Conferences; 
- Creating opportunities for ECR to be involved in the production of scientific synthesis reports, such as the Intergovernmental Panel on Climate Change's (IPCC) special report on the Ocean and Cryosphere in a Changing Climate and the Arctic Monitoring Assessment Programme (AMAP) Adaptation Actions for a Changing Arctic regional reports.

- Facilitating the application and selection process for various ECR opportunities, such as the IASC Fellows Program; or

- Enabling them to attend meetings of international polar-research focused organisations and planning groups as either observers or regular meeting participants. In addition to scientific committee and meeting planning activities, APECS also aims to create ECR opportunities at the science-policy interface by, for example, working with the Arctic Council Working Groups AMAP and CAFF with the goal to help ECRs understand how science is communicated to policy (Timm et al., 2017). Engagement of ECRs in CAFF and AMAP was through inclusion as co-authors in reports or observers at meetings and workshops (Provencher et al, 2012). APECS members actively contributed to the Arctic in Rapid Transition (ART) priority sheets, which outlined research of areas of high priority for the Arctic, for Third International Conference on Arctic Research Planning (ICARPIII) (Werner et al., 2016). In 2017, APECS cooperated with CAFF and IASC in the establishment of a new CAFF-IASC Science Policy Fellowship program in the lead up to the Arctic Biodiversity Congress 2018 organised by CAFF to provide two fellows with a direct sciencepolicy experience. The establishment of these opportunities may be considered a result of the increased visibility of ECRs within the polar science community since the 4th IPY and the success of APECS in providing a single voice for ECR in lobbying for such opportunities.

This paper documents the development of APECS over the past decade. We draw on the analysis of APECS documents and the results of two surveys: the 2015 Organisational Review Survey, which examined members perceptions of the value of various APECS activities and resources, and the 2017 EOC engagement survey, which assessed the impact 
that participating and organising EOC activities had on members' skill development. The aim of this paper is to demonstrate how APECS contributes to two of the identified legacies of the 4th IPY: promoting polar EOC activities and training ECRs (Krupnik et al., 2011). APECS provides members with unique opportunities to acquire and practise valuable soft skills e.g. leadership and communication, standing them in excellent stead for their future careers.

\section{Methods}

In addition to an assessment of the existing literature on the 4th IPY education and outreach activities (Kaiser, Zicus, \& Allen, 2010; Salmon et al., 2011; Provencher et al., 2011), the following methods were used to assess the participation of APECS members in EOC activities, whether engagement in these activities led to the acquisition of skill sets not gained through traditional education and academia, and to document APECS' training initiatives.

\subsection{APECS Member Database}

The APECS member database is an internal document containing basic personal information on APECS members. Up until June 2015, this database was maintained using a Joomla!® plugin for the APECS website. After June 2015, membership information has been curated using MailChimp® software, which makes it easier for members to update their membership information and unsubscribe. The present membership registration form collects information on, for example, career stage, gender, country of residence and discipline. Not of all of this information was collected in earlier versions of the registration form. The full form can be accessed on the APECS website (APECS Membership and Mailing List Registration, n.d.b.). Membership data can be downloaded at any time as a 'csv' file. Data for this study was downloaded on 31 December 2017. Duplicate membership subscriptions were removed from the combined database to obtain the total number of unique subscriptions. 


\subsection{APECS Documents}

Since 2007, APECS has produced an annual report that details all of the activities in which APECS and its National Committees have been involved with over the previous year. In addition, we consulted a summary report covering the period 2013-2016 which was produced for the Norwegian Research Council, who partly funded the APECS Directorate in Troms $\emptyset$ at that time. These reports were used to extract information on the trends pertaining to APECS' EOC activities. Quotes of personal experiences from those involved in events, workshops, and representative opportunities were included in these reports and are published on the website under 'Meeting Summary From Representatives' (APECS, n.d.c).

Two other key documents used in this paper were the Organisational Review Recommendations Report (Zaika et al., 2015) published in 2015 and the APECS Strategic Plan (APECS, 2016a) published in 2016, which incorporated the findings of the Organisational Review committee.

\subsection{Organisational Review Survey}

In order to inform the 2016-2020 APECS strategic plan an Organisational Review was conducted in 2015. As part of this process, the Organisational Review Committee launched an online survey in March 2015 to consult APECS members, mentors, and partners, as well as the wider polar community on APECS' work and how it could improve. For the purposes of this study, we focused on the set of questions aiming to assess the relevance of APECS' EOC activities and soft skill training (Table 1). The full set of questions are published in the Organisational Review Recommendation Report (Zaika et al., 2015).

\subsection{EOC Engagement Survey}


A survey was conducted in 2017 on the impact of APECS Education and Outreach activities. The survey was divided into three sections: 1) background demographics and involvement in APECS, 2) Education and Outreach activities not organised by APECS and 3) Education and Outreach activities organised by APECS. For sections 2 and 3, we collected information on the participation in and the organisation of education and outreach activities as well as the skills gained during each. In total, there were 16 questions with options for constrainedchoice answers and two open-ended questions inviting general comments (Table 2). The survey questions were developed internally but reflect options contained in constrainedchoice questions used in previous APECS surveys to enable cross-comparison of data.

The survey was posted online using Google forms from 19 August to 18 September 2017. The link to the survey was sent to the APECS mailing list which, at the time, included 2741 subscribers. In addition, the survey was announced via personal emails, the APECS website, and social media in order to reach the targeted respondent groups. Reminders to fill in the survey were sent through the main mailing list and through social media channels. Personal information collected comprised gender, career stage and previous level of involvement within APECS. Survey participants could volunteer to add a contact email address. All answers were kept confidential and stored in Google Drive.

Survey results were analysed in Microsoft Excel. The analysis focused on the relative proportion of participants selecting a particular option. To enable comparison with the organisational review survey, the numbers of survey participants selecting a specific answer were recalculated as a percentage of the total number of survey participants.

\subsection{Social Media}

Data on the statistics and demographics of APECS Social media derive from the platform based administrator analytical tools. APECS established its Facebook page and group in 
2006, and its Twitter account (@ PolarResearch) in 2009. Data regarding geographic and gender diversity were collected up to 2 January 2018. Data on hashtag usage was obtained from Twitter's search function.

\section{Results}

\subsection{APECS Membership Database}

Although the network began with only a few dozen members, APECS has expanded significantly over the past 10 years. Since its inception, 7,131 members from 102 countries and territories have subscribed to the APECS mailing list (Fig. 1; APECS, 2017a). The new membership database started in June 2017 has 3,152 subscribers from 67 countries ( 31 December 2017). Members wishing to stay on the APECS mailing list had to actively sign up to the new mailing list after June 2015. In the current membership database, $36 \%$ are members who re-joined after June 2015. In the period 2008-2017, an average of 713 new members joined the APECS mailing list each year. Since 2007, around 300 early career researchers from 32 countries have joined the APECS Council, Executive Committee, and Directorate while many more have been involved in its National Committees (currently 20, APECS, 2017b). These numbers demonstrate the wide reach of APECS, as well as the growth in recruitment of new members.

\subsection{Data on APECS activities}

Since 2007, APECS and its National Committees have organised 117 workshops and meetings and 89 panel discussions. The number of events organised annually has grown from 4 in 2007 to 26 in 2017 (up until 30 September) (Fig. 2; APECS, 2017b). APECS' webinars are recorded and catalogued as free and open access resources on the APECS website and Vimeo. More than 135 webinars are currently archived on the APECS website. 


\subsection{Organisational Review Survey}

The survey received 214 responses from 29 countries and the results directly fed into the APECS Strategic Plan (2016-2020). The results of the Organisational Review Survey are published in Zaika et al. (2015). In terms of APECS' activities, the most highly valued was APECS' work in creating ECR opportunities, with $83 \%$ members rating this activity as 4 or 5 on 5-point scale. The twin EOC activities of Polar Weeks and Antarctica Day were rated 4 or 5 by $48 \%$ of participants, and $64 \%$ rated the development of EOC resources as 4 or 5 . The top three highly valued skills (rated 5 on a 5-point scale) were communication (53\%), interdisciplinary knowledge (50\%) and networking (48\%).

\subsection{EOC Engagement Survey}

The survey received 112 responses, equating to a response rate of $4 \%$ of the membership at that time. $38 \%$ of respondents self-identified as having been actively involved in APECS activities (e.g serving on a committee, planning/organising an APECS event).

Since joining APECS, 79\% of survey respondents participated in an EOC activity external to APECS compared with 57\% participating in an APECS EOC activity. A smaller percentage of respondents had helped organise an activity: $68 \%$ for non-APECS and 37\% for APECS activities, respectively. A common feature in the data for both non-APECS and APECS activities is that it is most common for those who do get involved to participate in or organise 1-5 activities (Fig. 3). The five most common non-APECS activities to be involved in were classroom visits, workshops, science festivals, university open days, and writing for the general public. The results of the percentage of respondents participating in and organising APECS activities is shown in Fig. 4. $40 \%$ of survey participants have been involved in the IPY legacy project of Polar Weeks, which continues to be a significant event in the annual APECS calendar. 
The reported perception of skills gained from involvement in APECS activities varied depending on whether the respondent was participating in or organising the event. The three main skills gained by participating in an APECS EOC event were networking (75\%), communication $(71 \%)$ and interdisciplinary knowledge (65\%). Those who organised events also identified gaining those same three skills, but in addition they reported gaining leadership skills such as team management (Fig. 5). In response to a question on whether involvement in EOC activities had benefited their career, 77\% participants affirmed that it had, either by providing contacts, skills, or exposure to new opportunities.

\subsection{Survey demographics}

The demographics of survey participants closely matches those of the general APECS membership both in terms of career stage and gender (Fig. 6). In terms of career status, the organisational review survey had a greater contribution from senior APECS members, ('Other' and 'Faculty') than the overall membership and this reflects the fact that views from more senior members were actively sought. The EOC engagement survey had a higher relative proportion of doctoral students (47\%) compared to the general membership (37\%), possibly reflecting that this is the career stage when members are most actively engaged in EOC activities. The gender balance of the organisational review survey is very similar to that of the general membership (60:40 female/male split). Female participation in the EOC engagement survey, however, was greater at $70 \%$.

\subsection{Social Media}

APECS maintains a social media presence on both Facebook (Page and Group) and Twitter. The Facebook page is the official communication channel and has 3,998 fans (2 January 2018). The Facebook group on the other hand serves as a discussion forum for members and 
has 3,073 members of which 1,937 were active (posting, commenting, 'liking' posts) in the 60-day period prior to 2 January 2018. The APECS Twitter account has more followers than either Facebook platform with 5,861 followers. Gender distributions are very similar on all platforms (Facebook page 54\% female and 44\% male; Facebook group 57\% female and $43 \%$ male; Twitter $54 \%$ female and $46 \%$ male). Both cohorts are dominated by followers from North America and Europe, which reflects the geographic distribution of APECS members (Fig. 7).

The two Polar Weeks in 2017 each promoted a specific hashtag. The \#PolarPeople hashtag was used in 121 tweets during March Polar Week (20-26 March 2017), which equates to an average of 17.2 tweets per day. In total these tweets were retweeted 189 times and 'liked' 262 times. The \#PolarWorld hashtag was used in 42 tweets during September Polar Week (18-24 September 2017). Collectively these tweets were retweeted 129 times and 'liked' 110 times.

\section{Discussion}

Among the goals envisioned to last beyond the IPY were a continuation of raising the public profile of the polar regions, linking science and policy more effectively, improving opportunities for northerners, and sharing logistical information more broadly and more efficiently (Sloan \& Hik, 2008). Besides the many scientific achievements and enhanced scientific and political cooperation, the development of a new generation of polar scientists and engineers and a broad public interest in polar regions and issues were identified as legacies of IPY (Krupnik et al., 2011). As a direct realisation of this legacy, APECS has continued to build on the work started during IPY to promote polar education and outreach as well as the training of the next generation of polar researchers.

\subsection{Polar Education and Outreach - Raising the Public Profile of Polar Regions}


Effective public outreach has been identified as a key area for researcher improvement in order to meet societal obligations (Lubchenko, 1998; Leshner, 2007). Raising the public profile of polar regions by placing a strong emphasis on education and outreach initiatives was therefore one of the foci of the 4th IPY (Provencher et al. 2011; Salmon et al., 2011) and has acted as one of the key pillars of APECS activities since its foundation (APECS, 2016a). In the organisational review survey, $83 \%$ of respondents thought APECS' goal of "Developing effective future leaders in polar education and outreach" was important or very important (i.e., 4 or 5 on a 5-point scale). Indeed, in 2010, many APECS members were contributors to the Polar Resource Book, "Polar Science and Global Climate: An International Resources for Education and Outreach" (Kaiser et al, 2010). This book aimed to inspire educators, students, and polar researchers to continue their education and outreach efforts. In addition, the Polar Education and Outreach Catalogue, which acts as an archive of more than 550 education and outreach projects that took place during IPY, is hosted on the APECS website (Provencher et al. 2011), and was deemed valuable or very valuable (4 or 5 on a 5-point scale) by $51 \%$ of organisational review survey participants.

Today, the education and outreach momentum from the IPY is carried on by APECS, in conjunction with other organisations, like Polar Educators International (PEI) (Walton et al., 2013) and this is reflected in the participation and organisation of non-APECS EOC events (Fig. 3). Many early career researchers have been involved in extending the communication of their work and the importance of the Polar Regions to a wider audience, using both face-toface methods (e.g. presentations at schools, workshops on polar education, polar exhibitions) or various online platforms (Beck et al., 2014). A number of EOC survey participants commented that APECS provided a platform to learn and share outreach methods, for example: "Through involvement in APECS activities I have learned excellent new ways to communicate polar science that I have then utilized in my own outreach activities." 
Since 2011, APECS education and outreach efforts have focused largely on three annual dedicated campaigns in collaboration with the international research community: Two International Polar Weeks and Antarctica Day. Our survey results show that Polar Weeks and Antarctica Day were identified as the most popular EOC activities for members to be involved in, with $44 \%$ of respondents having been involved either in a participatory or in an organising role (Fig. 4). Perhaps surprisingly, given the numbers participating, only $19 \%$ of organisational review survey participants rated these two events as "very valuable" (Fig. 4). Further education and outreach activities, such as workshops (Fig. 4), were also organised by individual APECS members and National Committees (Xavier, Azinhaga, Seco, \& Fugmann, submitted; Caramello et al., 2017; Beck et al., 2014).

Both the number of National Committees involved in Polar Weeks and the number of activities continues to increase every year. In the September 2012 Polar Week, six national committees actively engaged around 4,000 students, 115 teachers and 25 scientists and educators through school visits (APECS, 2013). In September 2017, 11 national committees organised 16 activities, ranging from film viewings to symposia, in addition to the traditional school visits (APECS, 2017b). In 2015, 22 schools participated in the Antarctic Day Flag project (currently led by the UK Polar Network, UKPN) and 150 flags were created (APECS, 2016b). The flags, representing Antarctica or Antarctic values, are designed by school children and taken to Antarctica by researchers and photographed. Preliminary data for 2017 show the exponential success of this project with over 600 flags created from 100 schools (S. Buzzard, UKPN, personal communication, December 1, 2017).

Online social media is increasingly being used to broaden outreach (Benderley, 2014; Schiffman, 2012; Smith, 2014) and is a key component of APECS' Polar Weeks and Antarctica Day activities. Since 2015, a Reddit 'Ask Me Anything' (AMA) has been organised in conjunction with the Polar Weeks. This allows APECS to communicate with an audience who may not otherwise come into contact with polar research at all. The March 
2016 thread made it to the front page of Reddit with 1,911 votes, thereby showcasing current research themes to the general public. Twitter has been used to promote Polar Weeks amongst the wider community already engaged in polar regions by employing specific hashtags such as \#PolarPeople (March 2017 Polar Week) and \#PolarWorld (September 2017 Polar Week). The \#PolarPeople hashtag in particular was very successful at engaging the wider community with 121 tweets during the 7-day duration of the Polar Week with 189 retweets and 262 'likes'. The use of such hashtags encourages interaction, and provides both members and those with an interest in learning more about polar research a platform to engage. By engaging in these social media activities, APECS members not only help promote EOC activities but they learn how to tailor science messages to different audiences and effectively communicate science. $24 \%$ of those participating in EOC activities gained web-technology skills, including social media (Fig. 5).

\subsection{Capacity building for the Next Generation of Polar Researchers}

Capacity building and training the next generation of polar scientists is the other major IPY legacy that APECS has focused on. Since its creation, emphasis has been put on an experiential training of "soft skills" within APECS (Pope, Fugmann, \& Kruse, 2014). Members learn new skills by being involved in the process of planning and implementation of APECS activities, or by attending both online (e.g. webinars) and in-person training sessions (e.g. workshops) with experienced scientists or professionals. Skills they learn through this (e.g. networking and communication, Fig. 5) are not necessarily part of the standard curriculum of a graduate school or a postdoctoral fellowship in polar sciences but are often key elements of a successful career in both academic and non-academic professions (Kumar \& Hsiao, 2007; Weiler, 2007; Gordon, 2014). Indeed a survey by LeDee et al. 2011 found that informal methods, including self-teaching and peer-learning, were the primary means of acquiring new skills during postgraduate education. 
By having an inclusive leadership structure (Fig. 8), in which any actively contributing member is part of the leadership, APECS creates a low barrier to entry and tiered, progressive leadership roles for ECR to learn and grow, as well as a strong peer-to-peer support network. APECS' success is built on the enthusiasm and dynamism of its members, who suggest new ideas, and are provided with the support needed to follow them through. A participant in the organisational review survey commented that this enabled them "to practise leadership skills in an environment that feels safe". Through a variety of positions from local project coordinators for National Committees to the APECS Executive Committee, APECS members are exposed to challenges, an international, multidisciplinary network and opportunities that may differ from those normally encountered at their home institutions. Opportunities such as planning a workshop, scheduling and hosting an online meeting, crafting a partnership agreement with a potential partner organisation, or learning how to communicate science to students at a high school (potentially on the other side of the planet) all offer the chance for further skills development. Data from the EOC engagement survey indicates that rather than a small core of very active members who organise the majority of activities, there exists a large pool of members, who each organise a small number activities (Fig. 3). This highlights the effectiveness of APECS in training a broad pool of ECRs. Similar bottom-up organisational structures have been adopted in other early career organisations e.g. Young Earth System Scientists (YESS, Rauser, Schemann, \& Sonntag, 2015).

Many of the activities and projects organised by the APECS members on behalf of APECS are focussed on soft skill training for ECRs. By giving ECRs responsibility for organising these events, relevant themes are selected meaning that relevant skills are gained, not just by those organising them, but also by those who participate. For example, at the APECS World Summit in 2015 (Vick-Majors, Engelbertz, \& Fugmann, 2016), a dedicated session on data management was organised: a topic which was highlighted as of key importance during IPY and is ever more pertinent today (Friddell, Ledrew, \& Vincent, 2014; Mokrane \& Parsons 2014). Another example, and a theme highlighted during IPY (Krupnik, 2008), was the 
recognition by APECS members that collaborations with Indigenous community members could be improved. The resultant webinar series (part of the APECS Nordic Project, "Bridging Polar Early Career Researchers and Indigenous Peoples in Nordic Countries") was a solutions-focused activity that identified research challenges from the perspectives of ECRs and indigenous peoples (Sharp, Paquin, \& Fugmann, 2015). APECS webinars, many of which focus on the development of soft skills that may not be developed in formal training, are valued by APECS members, with $63 \%$ rating them as 4 or 5 (valuable or very-valuable) on a 5-point scale (Zaika et al., 2015). In the 2017 survey, 35\% of respondents had viewed an APECS webinar, while $11 \%$ had helped to organise one (Fig. 4).

The skill-set gained by those organising activities compared to only participating is quite different. As a result of participating in APECS' activities, the top 3 skills respondents perceived they had gained were: networking, communication and interdisciplinary knowledge. These skills were also the top three skills identified in the organisational review survey as being "very valuable" for polar researchers (Fig. 5). Those who organised activities were more likely to report gains in management related skills compared to those who only participated (Fig. 5), for example leadership (65 vs 14\%), team management (60 vs 19\%), time management (51 vs 15\%), and logistics and organisation (67 vs 25\%). EOC engagement survey participants stated: “ ...you learn how to organize small to large event and the (heavy) logistics that are hidden behind it." and "APECS definitely balanced out my academic scientific learning with needed skills in networking, communications, and team organization \& leadership", positively demonstrating the value of APECS' EOC activities in fostering skill development.

In addition to skill acquisition, APECS events have addressed key issues within polar science, garnering widespread attention within the wider polar community. Examples are a workshop at the International Conference on Arctic Science: Bringing Knowledge to Action entitled “Scientific Assessments: Process, Dissemination and Impact" (Timm et al., 2017) and a panel 
discussion at the 2010 SCAR OSC entitled "Antarctic Science: Role of SCAR in promoting early career research opportunities." The success of the latter event may be gauged by the increasing number of ECR representatives on SCAR committees; currently 14 ECR representatives on 7 committees, with 8 of these positions established since December 2016 (APECS n.d.d).

The work that APECS does to create ECR opportunities was identified as one of the most valued aspects of APECS with over $80 \%$ of the organisational review survey participants rating these positions as valuable or very valuable ( 4 or 5 on a 5 -point scale). APECS has worked with conference organisers to have ECR session co-conveners. For example, 31 out of the 43 sessions at the 2016 SCAR OSC had ECR session co-chairs. During 2017, 19 APECS members served as representatives to partner organisation committees, and 5 represented APECS at meetings (APECS, n.d.d). The feedback from the ECRs who participated in these international opportunities and from senior scientists has been overwhelmingly positive. Some examples of reactions:

- Karolina Paquin, ECR representative CAFF Board Meeting (2016): “The CAFF working group is a wonderful collection of experts ... their board meetings allow for young scientists to gain insight into how working groups function."

- Andreas Preußer, APECS Germany representative to the 26th Annual Meeting of the German National Committee SCAR / IASC (2017): “The invitation ...to participate ... can give valuable insights into national science activities and the translation of international science agreements and guidelines to a national level. Not less important - the NK SCAR/IASC is an ideal occasion to extend an ECS's professional network by facilitating communication with experienced senior researchers, federal institutions and/or funding agencies."

- Gabriela Roldan, ECR session co-chair SCAR Open Science Conference (OSC) 2016: "This has been an amazing experience for me, not just for the expertise gained ... but most of all for the helpfulness and collegiality from all involved". 
- Anonymous Organisational Review Survey respondent: "Through APECS positive engagements it has become mandatory to always ask "what early career scientist should we involve in this" rather than seeing this as an "unnecessary must". APECS has shown that high-level organizations can benefit from and rely on the organisational skills of young scientists."

- Anonymous Organisational Review Survey respondent: "In the past, few young people had the courage to step up and say I can contribute. APECS has helped give many young people a voice and a path to engagement."

- Anonymous Organisational Review Survey respondent: "I know of no other scientific field where a consistent and persevere [sic] presence of early career scientists and their perspectives is at the forefront as it is in polar sciences. I can only assume this is because of the work by APECS."

These quotes demonstrate the enormous value of ECR positions on boards and committees where ECR directly interact with the leading scientists in their field. The skills gained at the international level can then be used at a national level. For examples, APECS members who have been active at the international level have gone on to develop active public polar outreach programmes in non-traditional polar countries, for example Portugal, Bulgaria, and Brazil (Schiermeier, 2009; Xavier, in press). This in turn inspires the next generation of researchers.

Soft skills gained through both the work within APECS and through the training provided by its international partners have an impact on the careers of the ECRs, with $77 \%$ of the survey respondents noting a positive impact on them or their career. One of the EOC survey participants stated that: "APECS was the single most beneficial organization to my current career. I can't say enough good things about it. In my current faculty position, I strongly encourage any student who even mentions polar regions in passing to join APECS.” Developing soft skills can open up new career opportunities and our survey results show that $35 \%$ of the respondents were inspired to consider non-academic career pathways as a result of 
their involvement in APECS. A participant in the Organisational Review Survey supported this sentiment: "I saw the emergence of APECS when I was in responsibility position and I applauded this initiative for helping young scientist to enter the general carriers offered by the polar world both in science but also in logistics and more generally in international organization [sic]". The past presidents of APECS, for example, have gone on to careers not only in academia but also in consulting and science management (Table 3).

All of the initiatives discussed above contribute to the training of the next generation of leaders in both science and policy and have proven to be highly successful for the ECRs, the host organisations and APECS. Having ECRs participate in these activities not only builds their communication and management skills but also builds talent from within the organisation and supports institutional memory. Indeed, the involvement of ECRs in international research communities as contributors to projects, working groups, and organisations has recently been found to positively impact career success and retention of ECRs in polar science (Majaneva et al. 2016).

\subsection{Gender}

The lack of gender parity at higher levels of academia has been extensively highlighted (e.g. Barres, 2006; Larivière, Ni, Gingras, Cronin, \& Sugimoto, 2013; Shen, 2013) and popularised through the 'leaky pipeline' metaphor (e.g. Pell, 1996). In this context, it is therefore noteworthy that in the last decade 8 of 10 APECS Presidents were female (Table 3) and 11 of APECS' 20 National Committees in 2016-2017 were led by females (APECS, 2017). Women have been found to take on a greater proportion of service roles within university institutions, and this has been partly attributed to an inability to 'say no' (Guarino \& Borden, 2017). The fact that APECS, as a volunteer-led organisation, has a greater proportion of female leaders may indicate another factor: that female researchers are more likely to volunteer and actively seek out leadership opportunities that may not be readily available to them within their home 
institution. The bottom-up ethos of APECS allows participation of under-represented groups, increasing their opportunities and visibility on the international stage. Female role models have been identified as one factor in helping to improve retention of women in science, technology, engineering and mathematics (STEM) fields (Dasgupta, 2011; Drury, Siy \& Cheryan, 2011). A positive consequence, which would need to be tested and will need to wait until these ECRs are more senior in their careers, is that the high proportion of female leaders within APECS may help improve gender equality in the next generation of polar scientists.

\section{Conclusions and Perspectives}

Through its inclusive structure, ability to adapt to new technologies, and the desire to grow both national and international networks, APECS has been an active force in continuing the IPY legacy. The IPY legacy is twofold, having goals that advance both science and the public profile of the polar regions (Sloan \& Hik, 2008; Krupnik et al. 2011). Part of maximizing the scientific return requires coordinated international efforts that can engage diverse stakeholders (Kennicutt et al., 2014). APECS has been a model organisation in this regard, demonstrating the effectiveness of National Committees and the international secretariat in collaborating with a broad range of stakeholders. The International Polar Weeks and Antarctic Day initiatives are successful examples of the extended reach that can be realised through coordinated international efforts. The EOC activities organised by APECS reach an ever greater audience, enthusing and inspiring people about the Polar Regions. In this respect, it is safe to say that the legacy of IPY is alive and well.

The scientific momentum of IPY also generated a growth in ECR gaining degrees in polar science, engineering, and social sciences. Many of these ECR will be involved in, and also affected by, the Arctic and Antarctic science priorities in the coming decade (Kennicutt et al. 2014, ICARP III, 2015, Fritz et al., 2015). By participating in strong networks such as APECS, PYRN, and UKPN, ECRs gain an opportunity to be leaders in the polar science 
community and at the science-policy interface, by being on boards and planning committees of major international polar research-focused organisations including IASC, SCAR, EPB, and CAFF. In addition, APECS provides a unique platform for early career scientists to self-select themselves into opportunities where they can organise and participate in EOC initiatives and events. Through these opportunities, ECRs learn new skills, which benefit their career prospects. In addition, APECS has been a model of gender empowerment and inclusivity in polar science.

APECS is a volunteer-led organisation and this structure has had the added impact of increased participation of ECRs organising education and outreach events and thereby gaining valuable skills, in addition to their 'academic' skills which stand them in excellent stead when negotiating career decisions. As this IPY generation of ECRs are entering midcareer positions, there is a need and opportunity to harness this pool of skilled professionals.

\section{Acknowledgements}

We would like to thank José Xavier (University of Coimbra, Portugal), Jenny Baeseman (International Arctic Research Center), Narelle van der Wel (World Climate Research Programme) and Daniela Liggett (University of Canterbury, New Zealand) for comments on both the EOC survey design and earlier versions of this manuscript and for providing extremely valuable information on APECS' early years. We also thank everyone who took the time to contribute to the two surveys. This paper documents the tremendous amount of time which APECS members have volunteered to make the organisation what it is today and to deliver APECS' EOC activities: to all of you, thank you!

\section{Financial Support}


This research received no specific grant from any funding agency, commercial or not-forprofit sectors. 


\section{References}

APECS (2013) APECS Annual Report 2012-2013. Retrieved from:

https://drive.google.com/file/d/0B_O0QC8BfOA7V0NWQU5kMno3RjQ/view (accessed 10 January 2018)

APECS (2016a) APECS Strategic Plan 2016-2020. Retrieved from: http://apecs.is/who-weare/operating-procedures/strategic-plan-2016-2020.html (accessed 14 December 2017)

APECS (2016b) APECS Annual Report 2015-2016. Retrieved from:

https://apecs.is/images/Articles/Files/2016_10_28_Annual_Report_2015-2016_final.pdf (accessed 9 January 2018)

APECS (2017a) APECS Membership Database. Unpublished internal document, APECS, Potsdam.

APECS (2017b) APECS Annual Report 2016-2017. Retrieved from: https://apecs.is/who-weare/apecs-materials/publications/details/11/90.html (accessed 10 January 2018)

APECS (n.d.a) APECS Partners and Sponsors. Retrieved from: https://apecs.is/who-weare/partners-and-sponsors.html (accessed 20 December 2017)

APECS (n.d.b) APECS Membership and Mailing List Registration. Retrieved from: https://apecs.is/get-involved/join-apecs.html (accessed 18 December 2017) 
APECS (n.d.c) APECS Meeting Summary from Representatives. Retrieved from:

https://apecs.is/who-we-are/representatives/meeting-summary-from-representatives.html

(accessed 11 January 2018)

APECS (n.d.d) APECS Current Representatives. Retrieved from: https://apecs.is/who-weare/representatives/current-representatives.html (accessed 20 December 2017)

Baeseman J., \& Pope, A. (2011) APECS: Nurturing a New Generation of Polar Researchers. Oceanography, 24(3), 219. doi:10.5670/oceanog.2011.73.

Baeseman, J., Xavier, J., Lantuit, H., Taylor, A., Drobot, S., Else, B., ... Weiler, S. (2011) Early Career Researcher Activities During the 4th International Polar Year. In Krupnik, I., Allison, I., Bell, R., Cutler, P., Hik, D., López-Martinez, J., Rachold, V., Sarukhanian, E., \& Summerhayes, C. (Eds.) Understanding earth's polar challenges: International Polar Year 2007-2008. (pp. 511-522), University of the Arctic, Rovaniemi, Finland/CCI Press.

Barres, B. A. (2006) Does gender matter? Nature, 442, 133-136.

Beck, I., Huffman, L. T., Xavier, J. C. C., Walton, D. W. H. (2014) Education and Polar Research: Bringing Polar Science into the Classroom, Journal of Geological Resource and Engineering, 4, 217-221, doi:10.17265/2328-2193/2014.04.004

Benderly, B. L. (2014): To tweet or not to tweet?, Science, doi:10.1126/science.caredit.a1400246

Bulgaria \& Turkey (2017) Polar Scientific and Outreach Cooperation Between Bulgaria and Turkey, ATCM XL - IP138, 22 May-1 June 2017, Beijing, China. 
Caramello, N. D. A., Ivar do Sul, J. A., Souza, J. S., Santos, E. A., Piuco, R. C., Affonso, S. F., ... Costa, E. S. (2017). Ciência Polar e a Comunicação entre estudantes, educadores e cientistas. Revista Eletrônica Científica da UERGS, 3, 340-371.

Celebrating Antarctica (n.d.) Celebrating Antarctica. Retrieved from: http://celebratingantarctica.tumblr.com/ (accessed 27 December 2017)

Darlington, E., Waite, C., \& Balsdon, C. (2015) Postgraduate events as a building block for interdisciplinary research, Area, 47(4), 481-483. doi:10.1111/area.12227

Dasgupta, N. (2011) Ingroup experts and peers as social vaccines who inoculate the selfconcept: The stereotype inoculation model, Psychological Inquiry, 22(4), 231-246, doi:10.1080/1047840X.2011.607313

Drury, B. J., Siy, J. O. \& Cheryan, S., (2011) When do female role models benefit women? The importance of differentiating recruitment from retention in STEM, Psychological Inquiry, 22(4), 265-269, doi:10.1080/1047840X.2011.620935

Fritz, M., Deshpande, B. N., Bouchard, F., Högström E., Malenfant- Lepage, J., Morgenstern A., ... Weege, S. (2015) Brief Communication: Future avenues for permafrost science from the perspective of early career researchers. The Cryosphere, 9, 1715-1720.

Friddell, J. E., LeDrew, E. F. \& Vincent, W. F. (2014) The Polar Data Catalogue: Best practices for sharing and archiving Canada's polar data, Data Science Journal, 13, 1-7 doi:10.2481/dsj.IFPDA-01

Gordon, W. (2014) Developing Scientists' “Soft” Skills, EOS, 95(6), doi: 10.1002/2014EO060003 
Hambrook Berkman, J. \& A. Pope (2015): Celebrating Antarctica - A treaty protecting a continent. Retrieved from: http://celebratingantarctica.tumblr.com (accessed 15 December 2017)

Harrison, J. A., Cohen, J. H., Hinchey, E. Moerke, A., \& von Dassow, P. (2009) Developing and implementing an effective public outreach program, EOS, 90(38), 333-340.

ICARP III (2015) 3rd International Conference on Arctic Research Planning. Integrating Arctic Research - A Roadmap for the Future. Retrieved from:

https://icarp.iasc.info/images/articles/downloads/ICARPIII_Final_Report.pdf (accessed 27 December 2017)

Kaiser, B., Zicus, S., \& Allen, P. (2010). Polar Science and Global Climate: An International Resource for Education \& Outreach: Pearson Custom Publishing, Essex, UK

Kennicutt, M. C. II, Chown, S. L., Cassano, J. J., Liggett D., Massom, R., Peck, L S., ... Sutherland, W. J. (2014) Six priorities for Antarctic Science. Nature, 512, 23-25.

Krupnik, I. (2008) "The way we see it coming” Building the legacy of indigenous observations in IPY 2007-2008, in Smithsonian at the Poles: Contributions to International Polar Year Science, eds. Krupnik, I., Lang, M. A. \& Miller, S. E., p. 129-142. doi:10.5479/si.097884601X.11

Krupnik, I., Allison, I., Bell, R., Cutler, P., Hik, D., López-Martinez, J., ... Summerhayes, C. (2011). Understanding earth's polar challenges: International Polar Year 2007-2008, University of the Arctic, Rovaniemi, Finland/CCI Press 
Kumar, S., \& Hsiao, J. K. (2007). Engineers Learn "Soft Skills the Hard Way": Planting a Seed of Leadership in Engineering Classes. Leadership and Management in Engineering, 7(1), 18-23. doi:10.1061/(ASCE)1532-6748(2007)7:1(18)

Larivière, V., Ni, C., Gingras, Y., Cronin, B., \& Sugimoto, C. R., (2013) Global gender disparities in science, Nature, 504, 211-213.

LeDee, O. E., Barnes, R. T., Emanuel, R., Fisher, P.B. Henkel, S. K., \& Marlon, J. R., (2011) Training a new scientist to meet the challenges of a changing environment, EOS, 92, 135-136.

Leshner, A. I. (2007) Outreach training needed, Science, 315(5809), 161, doi:10.1126/science. 1138712

Lubchenko, J. (1998) Entering the Century of the Environment: A New Social Contract for Science, Science, 279(5350), 491-497, doi:10.1126/science.279.5350.49

Majaneva, S., Hamon, G., Fugmann, G., Lisowska, M \& J. Baeseman (2016): Where are they now? - A case study of the impact of international travel support for early career Arctic researchers. Polar Science, 10(3), 382 - 394. doi:10.1016/j.polar.2016.06.001

Mokrane M. \& Parsons, M. A. (2014) Learning from the International Polar Year to build the Future of Polar Data Management. Data Science Journal, 13, 88-93. doi:10.2481/dsj.IFPDA15

NERC (2017) Pathways to Impact. Retrieved from: http://www.nerc.ac.uk/funding/application/howtoapply/pathwaystoimpact/ (accessed 14 December 2017) 
Nielsen, H., Thornton, A., \& Fugmann, G. (2016) Digital outreach: Crossing borders online with the Association of Polar Early Career Scientists (APECS), XXXIV SCAR OSC Abstract Book, Kuala Lumpur, Malaysia, p 248, ISBN 978-0-948277-32-0. Retrieved from: https://www.scar.org/scar media/documents/outreach/communications/SCAR OSC 2016 A bstracts.pdf (accessed 15 December 2017)

NSF (2017) Recent changes to NSF proposal \& award policies. Retrieved from: https://www.nsf.gov/bfa/dias/policy/factsheets/por_mentor.pdf (accessed 12 January 2018)

Pell, A. N. (1996) Fixing the leaky pipeline: women scientists in academia, Journal of Animal Science, 74(11), 2843-2848, doi:10.2527/1996.74112843x

Pope, A. Fugmann, G. \& Kruse, F. (2014) Association of Polar Early Career Scientists Promotes Professional Skills, EOS, 95(24), 204.

Portugal, Brazil, Bulgaria, France, \& Kingdom, U. (2016). POLAR WEEKS: an Education and Outreach activity to promote Antarctic science and the Antarctic Treaty System ATCMXXXIX - IP007, 23 May-1 June 2016, Santiago de Chile, Chile.

Provencher, J., Baeseman, J., Carlson, D., Badhe, R., Bellman, J., Hik, D., ... Zicus, S. (2011). Polar Research Education, Outreach and Communication during the fourth IPY: How the 2007-2008 International Polar Year has contributed to the future of education, outreach and communication. Paris: International Council for Science (ICSU). Retrieved from: https://www.apecs.is/images/Articles/Files/ICSU IPY EOC Report 2011.pdf (accessed 14 December 2017) 
Provencher, J.F., Gantner, N., Schmale, J., Swanson, H. \& Baeseman, J.L., (2012) Early career researchers and mentors work together to shape the future of the Arctic Monitoring and Assessment Programme, Arctic, 65(1), 115-118.

Rauser, F., Schemann, V. \& Sonntag, S., (2015) Sustainable early-career networks, Nature Geoscience, 8, 745-746.

Salmon, R., Carlson, D., Zicus, S., Pauls, M., Basesman, J., Sparrow, E. B., ... Raymond, M. (2011) Education, outreach and communication during the International Polar Year 20072008: stimulating a global polar community, The Polar Journal, 1(2), 265-285, doi:10.1080/2154896X.2011.626629

Schiermeier, Q (2009) International Polar Year: In from the Cold, Nature, 457, 1072-1077, doi:10.1038/4571072a

Schiffman, D. S. (2012) Twitter as a tool for conservation education and outreach: what scientific conferences can do to promote live-tweeting, Journal of Environmental Studies and Sciences, 2(3), 257-262, doi:10.1007/s13412-012-0080-1

Schulz, N. (2008) The importance of soft skills: Education beyond academic knowledge. Journal of Language and Communication, 2(1), 146-154

Sharp, L., Paquin, K., Fugmann, G. and the APECS Nordic Team (2015): APECS Nordic Project 2013 - 2015 - Bridging Early Career Researchers and Indigenous Peoples in Nordic Countries - Final Report. Retrieved from: https://drive.google.com/file/d/1QP9-

kri_27hpsh6bnQm2A7TrJlq1ZZH6/view (accessed 10 January 2018)

Shen, H (2013) Mind the gender gap, Nature, 495, 22-24 
Sloan, K. K. \& Hik, D. (2008) International Polar Year as a Catalyst for Sustaining Arctic Research, Sustainable Development Law and Policy, 8(3), 4-7

Smith, D. K. (2014) iTube, YouTube, WeTube: Social Media Videos in Chemistry Education and Outreach, Journal of Chemical Education, 91, 1594-1599, doi:10.1021/ed400715s

Timm, K., Pope A., Smieszek, M., Fugmann, G. \& Zaika, Y. (2017) Arctic Science: From Knowledge to Action? The Polar Journal, 7(2), 428-429. doi:10.1080/2154896X.2017.1394122

Thomas, E. R., Baeseman, J., Lantuit, H., Xavier, J. \& Baker, N. (2008) Professional Development Training for Early Career Polar Researchers, EOS, 89(44), 434.

Vick-Majors, T. J., Engelbertz, S. \& Fugmann, G. (2016) Focus on the future of polar research, Eos, 97, doi:10.1029/2016EO042993.

Walton, D., Xavier, J. C., May, I., \& Huffman, L. (2013) Polar Educators International-A New Initiative for Schools. Antarctic Science 25 (4): 473

Werner, K., Fritz, M., Morata, N., Keil, K., Pavlov, A., Peeken, I., ... Wegner, C. (2016) Arctic in Rapid Transition: Priorities for the future of marine and coastal research in the Arctic, Polar Science, 10, 364-373, doi:10.1016/j.polar.2016.04.005

Weiler, C. S. (2007) Meeting Ph.D. Graduates' Needs in a Changing Global Environment, EOS, 88(13), 149-151 
Xavier, J. C., Azinhaga, P., Seco, J., \& Fugmann, G. (submitted). Polar weeks as an educational activity to boost science-educational links: example of Portugal. Polar Record.

Xavier, J. C., Gray, A. D \& Hughes, K. A. (in press). The rise of Portuguese Antarctic Research: implications for Portugal's status under the Antarctic Treaty. Polar Record.

Zaika, Y., Beck, I., Badhe, R., Dubinenkov, I., Kuznetsova, E., Pope, A., ... Xavier, J. (2015) Organisational Review Recommendations Report. Retrieved from: https://apecs.is/images/Articles/Files/APECSOrganizationalReviewReport_updated.pdf (accessed 15 December 2015)

Zicus, S., Almeida, M., Edwards, K., Hik, D., Huffman, L., Kaiser, B., ... Xavier, J. (2011) Early Career Researcher Activities During IPY. In Krupnik, I., Allison, I., Bell, R., Cutler, P., Hik, D., López-Martinez, J., Rachold, V., Sarukhanian, E., \& Summerhayes, C. (Eds.) Understanding earth's polar challenges: International Polar Year 2007-2008. (pp. 481-510), University of the Arctic, Rovaniemi, Finland/CCI Press. 
Table 1: Example of questions and answer options from Organisational Review Survey

\begin{tabular}{|l|l|}
\hline Question & Answer \\
\hline $\begin{array}{l}\text { How valuable do you believe the following education and outreach } \\
\text { (Includes Polar weeks and Antarctica Day) }\end{array}$ & 1 (not valuable) to 5 (very \\
\hline $\begin{array}{l}\text { How valuable do you believe the following online resources are to polar } \\
\text { researchers? }\end{array}$ & 1 (not valuable) to 5 (very \\
(Includes Polar Outreach Catalogue) & valuable) \\
\hline How valuable do you believe the following web-based activities are to \\
polar researchers? \\
(Includes webinars)
\end{tabular}


Table 2: Example of questions and answer options from 2017 survey

\begin{tabular}{|c|c|}
\hline Question & Constrained-choice answers \\
\hline \multicolumn{2}{|l|}{ APECS involvement section } \\
\hline $\begin{array}{l}\text { In what capacity were you involved in APECS? } \\
\text { (Please select as many as apply) }\end{array}$ & $\begin{array}{l}\text { - Member } \\
\text { - Member on an organising committee for an } \\
\text { - } \text { APECS event (online or in-person) } \\
\text { - National Committee Board member } \\
\text { - Council } \\
\text { - Executive Committee } \\
\text { - International Directorate } \\
\text { - Advisory Committee Member } \\
\text { - APECS Norge Board Member } \\
\text { - Other }\end{array}$ \\
\hline \multicolumn{2}{|l|}{ Education and Outreach activities section } \\
\hline $\begin{array}{l}\text { How many times have you PARTICIPATED in } \\
\text { education and outreach activities? }\end{array}$ & $\begin{array}{l}\text { Non-APECS activity before joining APECS } \\
0 / 1 \text { - } 5 \text { / } 6 \text { - } 10 \text { / } 11-15 / 15+ \\
\text { Non-APECS activity after joining APECS } \\
0 \text { / } 1 \text { - } 5 \text { / } 6 \text { - } 10 \text { / } 11-15 \text { / 15+ } \\
\text { APECS activity (incl. National Committee activities) } \\
0 \text { / } 1 \text { - } 5 \text { / } 6 \text { - } 10 \text { / } 11 \text { - } 15 \text { / } 15+\end{array}$ \\
\hline $\begin{array}{l}\text { What skills/experience have you gained by (CO-) } \\
\text { ORGANISING APECS events? }\end{array}$ & $\begin{array}{ll}\text { - } & \text { Networking } \\
\text { - } & \text { Communication } \\
\text { - } & \text { Interdisciplinary Knowledge }\end{array}$ \\
\hline
\end{tabular}




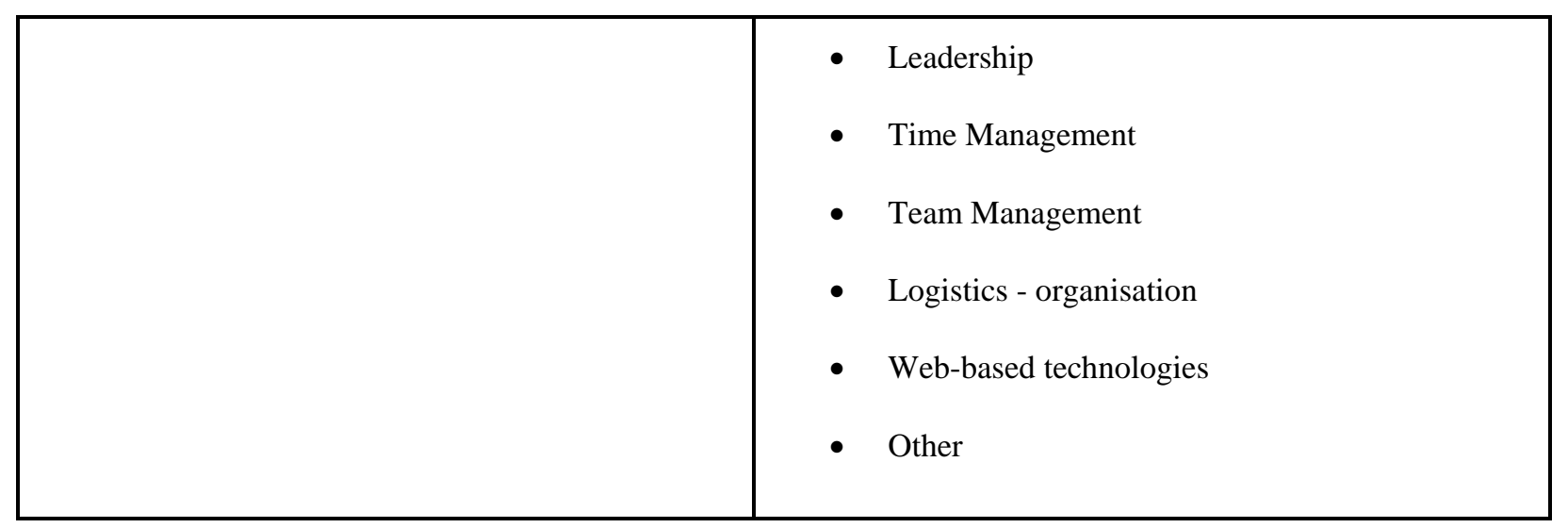


Table 3: The current job titles as of January 2018 of the first 11 APECS Presidents.

\begin{tabular}{|c|c|c|}
\hline Year & Name & Current position \\
\hline $2007-$ & Kriss Iversen & $\begin{array}{l}\text { Founder, SALT Environmental Consulting, Norway and Vice } \\
\text { President for Regional Development for UiT/Norway's Arctic } \\
\text { University }\end{array}$ \\
\hline $\begin{array}{l}2008- \\
2009\end{array}$ & $\begin{array}{l}\text { Daniela Liggett } \\
\text { (Haase) }\end{array}$ & $\begin{array}{l}\text { Senior Lecturer, Gateway Antarctica, University of Canterbury, New } \\
\text { Zealand }\end{array}$ \\
\hline $\begin{array}{l}2009- \\
2010\end{array}$ & Gerlis Fugmann & Executive Director, APECS, Germany \\
\hline $\begin{array}{l}2010- \\
2011\end{array}$ & Allen Pope & Executive Secretary, IASC, Iceland \\
\hline $\begin{array}{l}2011- \\
2012\end{array}$ & Yulia Zaika & $\begin{array}{l}\text { Station Manager for International Cooperation and Research } \\
\text { Associate, Khibiny Educational and Scientific Station, Russia }\end{array}$ \\
\hline $\begin{array}{l}2012- \\
2013\end{array}$ & Penelope Wagner & Researcher, Meteorological Institute, Norway \\
\hline $\begin{array}{l}2013- \\
2014\end{array}$ & $\begin{array}{l}\text { Christie Logvinova } \\
\text { (Wood) }\end{array}$ & Formerly PhD student, Clark University, USA \\
\hline $\begin{array}{l}2014- \\
2015\end{array}$ & $\begin{array}{l}\text { Jean-Sébastian } \\
\text { Moore }\end{array}$ & Assistant Professor, Université Laval, Canada \\
\hline $\begin{array}{l}2015- \\
2016\end{array}$ & $\begin{array}{l}\text { Ruth Vingerhagen } \\
\text { (Hindshaw) }\end{array}$ & Postdoctoral Fellow, University of Cambridge, UK \\
\hline $\begin{array}{l}2016- \\
2017\end{array}$ & Alice Bradley & $\begin{array}{l}\text { Research Associate, Thayer School of Engineering at Dartmouth, } \\
\text { USA }\end{array}$ \\
\hline $2017-$ & Hanne Nielsen & SCAR Fellow, visiting KTH Royal Institute of Technology, Sweden \\
\hline
\end{tabular}


Fig. 1: Cumulative growth of the number of unique APECS members (a) and number of countries (where members live and work) represented (b). The dashed grey line indicates when APECS established a new member database in June 2015. Data is from the APECS membership database accessed on 31 December 2017 (APECS, 2017a).

Fig. 2: Number of events (workshops, meetings and panel discussions) organised by APECS per year since 2007. Data for 2017 is until 30 September.

Fig. 3: The number of times survey participants $(n=112)$ participated in or organised EOC events.

Fig. 4: Percentage of survey participants in the EOC survey $(n=112)$ having participated in or organised EOC events. Note that National Committee (NC) activities are activities not associated with Antarctica Day or Polar Weeks. The stars indicate the percentage of respondents in the Organisational Review Survey $(n=214)$ rating the events as 5 very valuable on a 5-point scale. Here, $\mathrm{NC}$ activity refers to 'connections to local classrooms and outreach events' as these are typically organised by the NCs.

Fig. 5: Survey respondent reports of skills gained by organising or participating in APECS EOC activities. Figure shows the percentage of respondents who self-identified as organising activities $(n=43)$ or participating in activities $(n=85)$. Multiple answers were possible. 'Other' includes understanding of funding mechanisms, international collaboration, project management and challenges of a predominantly volunteer-led organisation. The stars indicate the percentage of respondents in the Organisational Review Survey $(n=214)$ rating the skills as 5 very valuable on a 5 -point scale.

Fig. 6: Comparison of the demographics of survey respondents to the current membership database: a) Career Stage b) Gender. 
Fig. 7: Overview of gender (circle; black $=$ female, grey $=$ male $)$ and geographic distribution on various APECS platforms (main mailing list $n=3,152$, Facebook page $n=3,998$ and Twitter $\mathrm{n}=5,861$ ). Geographic data for Twitter is only for the top 10 countries which represents $74 \%$ of users. More than half of APECS members are female and membership is dominated by North America and Europe. Data from 31 December 2017 (mailing list) and 2 January (Facebook and Twitter).

Fig. 8: The organisational structure of APECS as of October 2015. 